\title{
Risk factors, falls, and fracture of the distal forearm in Manchester, UK
}

ARC Epidemiology

Research Unit

T W O'Neill

D Marsden

A J Silman

and Department of Diagnostic Radiology, Manchester

University,

Manchester M13 9PT

J E Adams

Correspondence to

Dr T W O'Neill.

Accepted for publication November 1995

\begin{abstract}
Objective - To determine the risk factors associated with fracture of the distal forearm, and to evaluate the influence of falls on these risks.
\end{abstract}

Design - This was a case-control study.

Setting - Manchester, UK.

Participants - The cases were 62 white women aged 45-82 years who had sustained a fracture of the distal forearm and had attended local hospitals. Two control groups were studied - 50 women who had fallen onto the hand but had not sustained a fracture (recruited from the same source as those with fracture) and 116 women randomly selected from primary care age and sex registers in the catchment area of the hospitals. Both cases and controls were sent a letter inviting them to take part in the study. Data were collected by questionnaire completed by an interviewer.

Main results - Compared with the population control group, those with fracture were more likely to walk at a brisk pace (odds ratio $(O R)=3 \cdot 5 ; 95 \%$ confidence interval (CI) $1 \cdot 3,9 \cdot 6)$ though they had undertaken less physical activity at home or work on a daily basis throughout life $(O R=0.4$; $95 \% \mathrm{CI} 0.2,0.9)$. The risk associated with brisk walking was less marked when the cases were compared with fall controls. Other lifestyle factors including calcium intake, smoking, and alcohol consumption were not associated with fracture. Analysis of gynaecological and hormonal factors suggested that compared with population controls, those with fracture of the distal forearm had had fewer fertile years $(O R=$ $0.4 ; 95 \%$ CI $0.1,0.9)$ and were less likely to have used oral contraceptives $(O R=0 \cdot 3$; 95\% CI 0.1, 0.9).

Conclusions - The data highlight the need for caution when advising middle aged and elderly subjects about exercise. Such advice should be combined with practical information about the prevention of falls. Hormonal factors seem to be additional determinants of fracture. Other lifestyle interventions seem unlikely to play an important part in preventing distal forearm fracture.

( $¥$ Epidemiol Community Health 1996;50:288-292)

Fracture of the distal forearm is the most frequent osteoporotic fracture in perimenopausal and postmenopausal white women up to the age of 75 years in the USA and northern Europe. 1 Despite this, however, and in contrast to the detailed information on risk factors for hip fracture, relatively little is known about the lifestyle and hormonal determinants of this common fracture.

Regular physical activity and high calcium intake, measures that may preserve bone mass, offer the main immediate population based strategy for hip fracture, the most important consequence of osteoporosis. ${ }^{2-4}$ Their potential role in preventing distal forearm fracture, however, is not well established. Distal forearm fracture occurs at a younger age than hip fracture and in most cases results from a fall onto the outstretched hand. ${ }^{5}$ Such falls are thought to occur as a result of increased forward momentum such as during periods of rapid walking. ${ }^{6}$ Thus the overall effect of physical activity might be to increase the risk of fracture by increasing the susceptibility to falls onto the hand, possibly countering the risk reduction achieved by exercise in preserving bone mass. There is conflicting evidence from published reports. Kelsey, ${ }^{7}$ in a large prospective study, found an increased risk of fracture due to frequent walking, while Mallmin, ${ }^{8}$ in a case-control study, found no evidence of an influence of daily physical activity, other than that moderate levels of activity in females were protective. Hence there is no current, clear, scientific basis for recommending physical activity as a preventive measure for distal forearm fracture and some concern that measures which have been proposed as part of a population strategy against hip fracture ${ }^{4}$ might, paradoxically, increase the risk of distal forearm fracture.

Epidemiological and clinical studies indicate that oestrogen therapy protects against fracture, ${ }^{9-11}$ and there is evidence that variables related to increased exposure to oestrogen such as older age at menopause and childbearing are protective. $^{78}$ There is, however, debate about the potential benefit of the oral contraceptive pill on both forearm bone density and fracture. ${ }^{12-15}$ In addition, there is relatively little information on the risks associated with other lifestyle characteristics including smoking and alcohol.

We studied an unselected series of subjects who presented to hospital after having fallen and sustained a fracture of the distal forearm. We compared their physical activity, lifestyle, and hormonal characteristics with subjects who had fallen onto their hand but had not sustained a fracture, and a group of population controls.

\section{Methods}

DESIGN AND SUBJECTS

A case-control design was used for the study. White women aged 45 years and over who had 
sustained a fracture of the distal forearm were identified from accident and emergency records of hospitals in south Manchester between October 1991 and March 1993. In all cases, a diagnosis of distal forearm fracture was confirmed by radiograph. Two control groups were chosen. The first was a "fall" control group comprising women of similar age range who had attended the same accident and emergency departments with a fall onto the hand during the same period but who had not sustained a fracture. The second was a "population" control group of women randomly selected from the registers of two large general practices in the catchment area of the hospitals.

Cases and both groups of controls were invited to participate by letter, and one repeat letter sent to those who did not respond to the first. Those who agreed to take part were interviewed at home by one of two trained interviewers.

We aimed to study 65 subjects with wrist fracture. This was the number required to detect an association with an odds ratio of 2.5 or greater at a $5 \%$ significance level and $80 \%$ power (assuming two controls per case, and an exposure variable with $30 \%$ prevalence in the non-fracture group).

Ethical approval for the study was obtained from the central Manchester and Salford district health authorities ethical committees.

\section{QUESTIONNAIRE}

The questionnaire covered aspects of personal and medical history, reproductive and hormonal characteristics, smoking habits, alcohol consumption, dietary calcium intake, and physical activity. Detailed explanation of some of these variables is outlined below. The diagnosis of diabetes was obtained by enquiring whether a subject had been told they had this disease by their general practitioner. Subjects were asked about treatment with steroids for a period of three or more months. Self reported health status was assessed by asking a subject to describe her general health status (very good, good, satisfactory, poor, very poor). Immobility was assessed by asking if a subject had in the past spent more than 30 consecutive days in bed most or all of the time. A detailed validated frequency and amount questionnaire was used to assess calcium intake. ${ }^{16} \mathrm{~A}$ number of parameters of physical activity were assessed as follows: average walking speed (very slow, easy, normal, brisk); the number of hours spent walking outdoors daily (none, 1-30 minutes, 30-60 minutes, 1-2 hours, $>2$ hours); and the maximum level of physical activity undertaken at home and at work on a daily basis (light, moderate, heavy, very heavy), assessed during three age periods, 18-25 years, 25-45 years, and 45 years and over. Each subject's height and weight were measured using standard equipment.

\section{STATISTICAL ANALYSIS}

Age at menopause was taken as the date of the last period, though women with a hysterectomy or hysterectomy and unilateral oophorectomy coincident with their last period were excluded. The number of fertile years was calculated by subtracting the age at menarche from the age at menopause. A small proportion of women had not yet reached menopause ( 2 cases, 3 fall controls, and 15 population controls) and these were excluded from the analysis of fertile years. For the main analysis, age at menopause, menarche, and number of fertile years were categorised into tertiles.

The level of physical activity undertaken at work and at home was analysed by deriving an overall lifetime activity score, obtained by summing the values from the individual age periods (for each age period, $1=$ light, $2=$ moderate, $3=$ heavy, $4=$ very heavy (range 3 12)). Body mass index $\left(\mathrm{kg} / \mathrm{m}^{2}\right)$ was calculated.

The $\chi^{2}$ test for trend was used to explore for trends in the ordinal multi category variables. Logistic regression was used to determine the independent effects of the putative risk factors after controlling for age (as a continuous variable), with the outcome (fracture/control) as the dependent variable. Parameters were estimated by the maximum likelihood method. Adjusted odds ratios and their $95 \%$ confidence intervals $(95 \% \mathrm{CI})$ for fracture were calculated from the logistic coefficients and their standard errors. The odds ratio (OR) is a measure of the degree of association between an exposure and an outcome variable: an OR greater than 1 implies an increased likelihood of fracture as a result of a particular exposure variable, and OR less than 1 indicates that a variable is protective. The magnitude of the OR gives an indication of the strength of the association. An OR of 2 indicates a twofold increase in risk, an OR 0.5 indicates a twofold reduction in risk. The $95 \% \mathrm{CI}$ represents the range of values within which the true OR would be expected to lie with $95 \%$ probability; if the range embraces unity the results may have arisen because of chance. A multivariate model was used to determine the relative contribution of components of physical activity and general health, to the risk of fracture. Analyses were performed using SPSS/PC and STATA. ${ }^{17}$

\section{Results}

SUBJECTS

There were 62 women with fracture of the distal forearm (mean (SD) age 62.9 (8.8) years), 116 population controls (mean age $61 \cdot 1(8 \cdot 7)$ years), and 50 fall controls (mean age $60 \cdot 8$ $(7 \cdot 7)$ years). Both fracture cases and fall controls were recruited consecutively. The response rate for participation in the population control group was $41 \%$.

Table 1 presents the age adjusted odds ratio (OR) and $95 \% \mathrm{CI}$ for the relationship between gynaecological/hormonal variables and distal forearm fracture for both control groups.

An increased number of fertile years $(\geq 38$ years $\mathrm{v} \leq 32$ years) was associated with a decreased risk of fracture for both population $(\mathrm{OR}=0.4 ; 95 \% \mathrm{CI} 0.1,0.9)$ and fall control groups $(O R=0 \cdot 3 ; 95 \%$ CI $0 \cdot 1,0 \cdot 9)$. Compared with the population controls, those with distal 
Table 1 Risk of distal forearm fracture: gynaecological and hormonal variables. Odds ratios (OR) and $95 \%$ confidence intervals (95\% CI) (age adjusted).

\begin{tabular}{|c|c|c|c|}
\hline Variable & Unit & $\begin{array}{l}\text { Population controls } \\
\text { OR }(95 \% \text { CI) }\end{array}$ & $\begin{array}{l}\text { Fall controls } \\
\text { OR }(95 \% \text { CI) }\end{array}$ \\
\hline Age at menarche $(y)$ & $\begin{array}{l}\leq 12 \\
13-14 \\
\geq 15 \\
p=0.05\end{array}$ & $\begin{array}{l}\text { Reference } \\
1 \cdot 4(0 \cdot 7,3 \cdot 1) \\
2 \cdot 1(0.9,4 \cdot 6)\end{array}$ & $\begin{array}{l}\text { Reference } \\
2 \cdot 2(0 \cdot 9,5 \cdot 7) \\
2 \cdot 1(0 \cdot 8,5 \cdot 5) \\
p=0 \cdot 08\end{array}$ \\
\hline Age at menopause (y) & $\begin{array}{l}\leq 47 \\
48-51 \\
\geq 52 \\
\text { NS }\end{array}$ & $\begin{array}{l}\text { Reference } \\
1 \cdot 2(0 \cdot 5,2 \cdot 8) \\
1 \cdot 0(0 \cdot 4,2 \cdot 4)\end{array}$ & $\begin{array}{l}\text { Reference } \\
0.4(0.1,1 \cdot 4) \\
0.3(0.1,1 \cdot 1) \\
\mathrm{p}=0.08\end{array}$ \\
\hline Fertile period* $(y)$ & $\begin{array}{l}\leq 32 \\
33-37 \\
\geq 38 \\
\mathrm{p}<0.05\end{array}$ & $\begin{array}{l}\text { Reference } \\
0 \cdot 8(0 \cdot 4,2 \cdot 0) \\
0.4(0.1,0.9)\end{array}$ & $\begin{array}{l}\text { Reference } \\
0.5(0.2,1.6) \\
0.3(0.1,0.9) \\
\mathrm{p}<0.05\end{array}$ \\
\hline $\begin{array}{l}\text { Oral contraceptive pill } \\
\text { Hormone replacement therapy }\end{array}$ & $\begin{array}{l}\text { Yes v No } \\
\text { Yes v No }\end{array}$ & $\begin{array}{l}0 \cdot 3(0 \cdot 1,0 \cdot 9) \\
0 \cdot 8(0 \cdot 3,2 \cdot 0)\end{array}$ & $\begin{array}{l}0 \cdot 7(0 \cdot 2,2 \cdot 4) \\
0 \cdot 9(0 \cdot 3,2 \cdot 8)\end{array}$ \\
\hline
\end{tabular}

$\chi^{2}$ test for trend.

${ }^{*}$ Fertile period $=$ age at menopause - age at menarche

Table 2 Risk of distal forearm fracture: physical activity variables and general health in the fracture group compared with the population controls. Odds ratios (ORs) $95 \%$ confidence intervals (95\% CI)

\begin{tabular}{|c|c|c|c|c|}
\hline Variable & $\begin{array}{l}\text { Control } \\
\text { No }\end{array}$ & $\begin{array}{l}\text { Case } \\
\text { No }\end{array}$ & $\begin{array}{l}\text { Age adjusted } \\
\text { OR }(95 \% \text { CI) }\end{array}$ & $\begin{array}{l}\text { Adjusted for age and } \\
\text { other variables* } \\
\text { OR }(95 \% \text { CI) }\end{array}$ \\
\hline \multicolumn{5}{|l|}{ Walking speed } \\
\hline Very slow/easy & 39 & 17 & Reference & Reference \\
\hline Normal & 51 & 19 & $1 \cdot 1(0 \cdot 5,2 \cdot 5)$ & $1 \cdot 2(0 \cdot 5,3 \cdot 1)$ \\
\hline Brisk & $\begin{array}{l}25 \\
\mathrm{p}<0.05\end{array}$ & 26 & $3 \cdot 3(1 \cdot 4,7 \cdot 9)$ & $3.5(1.3,9.6)$ \\
\hline \multicolumn{5}{|l|}{ Time walking/d } \\
\hline$<30 \mathrm{~min}$ & 71 & 29 & Reference & Reference \\
\hline $30-60 \mathrm{~min}$ & 29 & 18 & $1 \cdot 5(0 \cdot 7,3 \cdot 2)$ & $1 \cdot 7(0 \cdot 8,4 \cdot 0)$ \\
\hline$>60 \mathrm{~min}$ & $\begin{array}{l}16 \\
p<0.5\end{array}$ & 15 & $2 \cdot 2(1 \cdot 0,5 \cdot 1)$ & $2 \cdot 2(0.9,5 \cdot 5)$ \\
\hline \multicolumn{5}{|c|}{ Lifetime activity score $†$} \\
\hline $3-4$ & 21 & 23 & Reference & Reference \\
\hline $5-6$ & 48 & 17 & $0.3(0 \cdot 1,0 \cdot 8)$ & $0 \cdot 3(0 \cdot 1,0 \cdot 7)$ \\
\hline$\geq 7$ & $\begin{array}{l}44 \\
\text { NS }\end{array}$ & 21 & $0.4(0.2,1.0)$ & $0.4(0.2,0.9)$ \\
\hline \multicolumn{5}{|l|}{ General health } \\
\hline Very good & 37 & 24 & Reference & Reference \\
\hline Good & 41 & 20 & $0.7(0.3,1.6)$ & $0.9(0.4,2.0)$ \\
\hline Satisfactory & 20 & 11 & $0 \cdot 8(0 \cdot 3,2 \cdot 0)$ & $0.9(0.3,2.5)$ \\
\hline Very poor/poor & $\begin{array}{l}18 \\
\text { NS }\end{array}$ & 7 & $0.5(0.2,1.5)$ & $1 \cdot 0(0 \cdot 3,3 \cdot 1)$ \\
\hline
\end{tabular}

$\chi^{2}$ test for trend.

* Walking speed, walking time, lifetime activity score, general health, BMI

t Physical activity both a w work and at home (light $=1$, moderate $=2$, heavy $=3$, very heavy $=4$ );

Score derived by summing values over three age groups $(18-25 \mathrm{y}, 25-45 \mathrm{y}, 45+\mathrm{y})$.

Table 3 Risk of distal forearm fracture: physical activity variables and general health in fracture cases compared with the fall controls. Odds ratios (OR), 95\% confidence intervals $(95 \% \mathrm{CI})$

\begin{tabular}{|c|c|c|c|c|}
\hline Variable & $\begin{array}{l}\text { Control } \\
\text { No }\end{array}$ & $\begin{array}{l}\text { Case } \\
\text { No }\end{array}$ & $\begin{array}{l}\text { Age adjusted } \\
\text { OR }(95 \% \text { CI })\end{array}$ & $\begin{array}{l}\text { Adjusted for age and } \\
\text { other variables* } \\
\text { OR }(95 \% \text { CI) }\end{array}$ \\
\hline \multicolumn{5}{|l|}{ Walking speed } \\
\hline Very slow/easy & 18 & 17 & Reference & Reference \\
\hline Normal & 17 & 19 & $1.4(0.5,3.6)$ & $1.4(0.5,4 \cdot 0)$ \\
\hline Brisk & $\begin{array}{l}15 \\
\text { NS }\end{array}$ & 26 & $2.3(0.9,6.0)$ & $2 \cdot 2(0 \cdot 7,6 \cdot 7)$ \\
\hline \multicolumn{5}{|l|}{ Time walking/d } \\
\hline$<30 \mathrm{~min}$ & 24 & 29 & Reference & Reference \\
\hline $30-60 \mathrm{~min}$ & 17 & 18 & $0.9(0.4,2.2)$ & $1 \cdot 0(0.4,2 \cdot 5)$ \\
\hline$>60 \mathrm{~min}$ & NS & 15 & $1.3(0.5,3.6)$ & $1.3(0.5,3.9)$ \\
\hline \multicolumn{5}{|c|}{ Lifetime activity score } \\
\hline $3-4$ & 14 & 23 & Reference & Reference \\
\hline $5-6$ & 18 & 17 & $0.6(0.2,1.5)$ & $0.5(0.2,1.5)$ \\
\hline$\geq 7$ & 17 & 21 & $0.8(0.3,2.1)$ & $0.8(0.3,2 \cdot 2)$ \\
\hline & NS & & & \\
\hline \multicolumn{5}{|l|}{ General health } \\
\hline Very good & 13 & 24 & Reference & Reference \\
\hline Good & 19 & 20 & $0.6(0.2,1.4)$ & $0.7(0.3,1.8)$ \\
\hline Satisfactory & 12 & 11 & $0.5(0.2,1.4)$ & $0.6(0.2,1.8)$ \\
\hline Very poor & 6 & 7 & $0.5(0 \cdot 1,2 \cdot 0)$ & $1 \cdot 0(0 \cdot 2,5 \cdot 1)$ \\
\hline
\end{tabular}

*Walking speed, walking time, lifetime activity score, general health, BMI. tSee footnote table $2 . \chi^{2}$ test for trend. forearm fracture were less likely to have used the oral contraceptive pill $(\mathrm{OR}=0 \cdot 3 ; 95 \% \mathrm{CI}$ $0 \cdot 1,0 \cdot 9$ ).

An increased age at menopause ( $\geq 52$ years $\mathrm{v} \leq 47$ years) was associated with a threefold reduction in the risk of fracture for the fall controls. For both population and fall control groups an increased age at menarche $(\geq 15$ years $\mathrm{v} \leq 12$ years) was associated with a twofold increased risk of fracture, however the confidence intervals around these estimates included 1 .

There was no association between the use of hormone replacement therapy, pregnancy, or breast feeding and distal forearm fracture in either of the control groups.

Compared with the population controls, those with fracture were twice as likely to have been confined to bed for a period of 30 or more days (OR $=2 \cdot 3$; $95 \%$ CI $1 \cdot 0,5 \cdot 7)$. However, none of the other lifestyle or personal history variables, including diabetes, steroid use, smoking, alcohol consumption, and dietary calcium intake, or any of the anthropometric variables, including body mas index, were significantly associated with fracture in either control group.

Tables 2 and 3 show the age adjusted ORs for the relationship between fracture, physical activity, and general health. Compared with the population controls, there was an increased risk of fracture associated with a brisk walking speed (OR $=3 \cdot 3 ; 95 \% \mathrm{CI} 1 \cdot 4,7 \cdot 9)$ and walking more than one hour per day $(\mathrm{OR}=2 \cdot 2 ; 95 \%$ CI $1 \cdot 0,5 \cdot 1)$. In addition, those with a lifetime activity score of 7 or more had a reduced risk of fracture compared with those with score of 4 or less $(\mathrm{OR}=0 \cdot 4 ; 95 \% \mathrm{CI} 0 \cdot 2,1 \cdot 0)$. Compared with the fall controls, there was a twofold increase in risk of fracture associated with brisk walking, but the confidence interval around this estimate included unity.

To determine the independent effect of the physical activity variables in determining fracture risk, a multivariate model was used. Adjusting for body mass index, general health, and the other physical activity variables did not alter the magnitude of the ORs associated with these variables. For the population controls however, the confidence interval around walking $>1$ hour per day no longer excluded unity.

Poor general health was protective for fracture for both control groups in the univariate analysis, but the protective effect disappeared after adjusting for other physical activity variables and body mass index, suggesting confounding by these variables.

\section{Discussion}

In this case-control study some forms of activity, including brisk walking and increased time spent walking daily, were associated with an increased risk of distal forearm fracture. Variables relating to increased oestrogen exposure, including increased number of fertile years and use of the oral contraceptive pill, were protective. Lifestyle variables such as smoking and alcohol consumption appeared unimportant. 
The reason for using two control groups was to explore the influence of falls on the risk factors for distal forearm fracture. The population group allowed us to determine the risk factors for fracture; the fall group whether these risk factors were independent of the risk of falling. There are, however, some methodological issues to be addressed. Only a few falls come to medical attention and selection factors may have influenced those who attended hospital after a fall, resulting in possible bias. The advantages of using this source of control group, however, were that the area of residence was broadly similar to that of the fracture cases and the alternative source, sampling from the population base, would have required a very much larger and costly screening survey. Selection is unlikely to have been a major factor in the other study groups; most individuals in the UK are registered with a general practitioner and virtually all cases of distal forearm fracture are treated at hospital.

In contrast to other studies ${ }^{8}$ we did not exclude those with a history of previous fracture. The inclusion of such individuals would tend, if anything, to make the groups more similar with regard to individual risk factor profiles and therefore bias the results towards the nul and away from finding significant associations.

Both fracture and fall cases were recruited consecutively from local hospitals while the population controls were recruited from general practice registers. It is possible that those who participated in the study had differing lifestyle characteristics, including physical activity, from those who were invited but who did not participate. This would result in response bias if the distribution of such characteristics differed among the three study groups, independently of the risk of fracture. The distribution of the common lifestyle factors, diet, smoking, and alcohol consumption was similar, however, in the responders for both control groups providing some evidence against serious response bias. Nevertheless some caution is required in interpreting the results.

In this study the response rate was low $(41 \%)$. This may be partly due to the fact that only one reminder letter was sent. In health surveys undertaken by our group, at least two reminders are sent out, and the level of response tends to increase with the number of reminders. However, in this study it was felt inappropriate to contact individuals with a recent fracture on more than one occasion, and to ensure comparability a similar approach was used for the two control groups. Given that any factors which may affect the level of response are likely to be similar for the three study groups it seems unlikely that the response level would have an important effect on the results of the comparisons between these groups.

The sample size of the study was relatively small and had therefore limited power to detect significant associations between variables. A larger sample would have resulted in a narrowing of the confidence intervals around the observed odds ratios.

The study was conducted prospectively and in most cases within eight weeks of the fracture or fall event, reducing the likelihood of any true subject change in exposure characteristics.

It is possible that risk factors for distal forearm fracture vary with age; reflecting, for example, the differing influences of peak bone mass and subsequent rate of bone loss on the risk of fracture. The numbers of subjects studied here were, however, too small to permit detailed analysis of risk factors within individual age strata and further studies would be required to address this.

Osteoporosis and falls are two of the main aetiological factors in the pathogenesis of age related fractures. Physical activity is thought to reduce the risk of hip fracture by a beneficial effect on bone mass, ${ }^{41819}$ and possibly by reducing the risk of dangerous falls. ${ }^{2021}$ The effect on distal forearm fracture, however, is less clear. Whereas physical activity is also associated with preservation of forearm bone mass, ${ }^{22}{ }^{23}$ activities such as rapid walking are thought to increase the risk of falling onto an outstretched hand, and therefore susceptibility to forearm fracture. There are relatively few published data; Mallmin ${ }^{8}$ found little effect of daily physical or leisure activity (apart from moderate daily activity which was protective). Kelsey, ${ }^{7}$ in a prospective study in a slightly older population, showed, however, that frequent walking was associated with an increase risk of fracture. In our study, compared with population controls, increased current levels of walking, including speed and amount, were associated with fracture. The risk associated with these variables decreased after controlling (in the design) for falls to the hand, indicating that the link with fracture is partly due to an increased risk of falls onto the hand.

In contrast to walking, heavy or very heavy levels of physical activity undertaken at home or work throughout adult life were protective. A similar finding was observed by Kelsey (who looked at frequency rather than intensity). ${ }^{7}$ This is probably mediated by an increase in bone strength, though in our study the effect was less marked in the fall controls suggesting that increased lifetime physical activity may protect against fracture by reducing the risk of falls onto the hand.

Our data are consistent with published studies $^{789-11}$ that show a protective effect of variables related to oestrogen excess. In our study an increased number of fertile years was the strongest factor. Studies looking at the effect of the oral contraceptive pill on skeletal health have produced discrepant findings. Some report a beneficial effect on radial bone mass, ${ }^{1415}$ others no effect on bone mass or fracture risk. ${ }^{12}{ }^{13}$ Our data indicate a beneficial effect on fracture risk, though the amount of oestrogen which was used in oral contraceptive pills during the time when the women in our study were likely to have been taking them was higher than doses currently in use and the extent to which our results are generalisable to the present day is uncertain.

We conclude that some forms of activity, including increased speed and amount of walking, are associated with an increased risk of distal forearm fracture, though this seems in 
part due to an increased risk of falls to the hand. Exercise is regarded as an important component of preventive strategies targeted at hip fracture, ${ }^{4}$ the most important consequence of osteoporosis. Our data highlight the need for caution when advising middle aged and elderly subjects about exercise, and particularly walking. Such advice should be combined with practical information about the prevention of falls. Lifestyle interventions seem unlikely to play an important role in prevention of distal forearm fracture.

This study was supported by a grant from the Kershaw trust. We would like to Dr WP Tamkin, Dr DR Bodey, and their partners and the staff of the general practices in the study; Professor D Yates, Dr R Morton, Dr B Ryan, Mr Hirst, and the
staff of the accident and emergency departments at Withington hospital, Hope Hospital, and Manchester Royal Infirmary for assisting in recruitment of subjects; Heather Fox for assisting in administration of the study; and Gail Dennehy for her assistance in data collection.

1 Cummings SR, Kelsey JL, Nevitt MC, O'Dowd KJ. Epidemiology of osteoporosis and osteoporotic fractures. Epidemiol Rev 1985;7:178-208.

2 Cooper C, Barker DJP, Wickham C. Physical activity, muscle strength, and calcium intake in fracture of the proximal femur in Britain. BMf 1988;297:1443-6.

3 Lau E, Donnan S, Barker DJP, Cooper C. Physical activity and calcium intake in fracture of the proximal femur in Hong Kong. $B M F$ 1988;297:1441-3.

4 Law MR, Wald NJ, Meade TW. Strategies for prevention of osteoporosis and hip fracture. BMF1991;303:453-61.

5 Cooper C. Epidemiology and public health impact of osteoporosis. In: Reid DM, ed. Baillière's clinical rheumatology. porosis. In: Reid DM, ed. Bailliere's clinical

6 Cummings SR, Nevitt MC. A hypothesis: the causes of hip fractures. F Gerontol 1989;44:M107-11.

7 Kelsey JL, Browner WS, Seeley DG, Nevitt MC, Cummings SR, for the Study of Osteoporotic Fractures Research SR, for the Study of Osteoporotic Fractures Research
Group. Risk factors for fractures of the distal forearm and proximal humerus. Am $\mathcal{F}$ Epidemiol 1992;135:477-89.
8 Mallmin H, Ljunghall S, Persson I, Bergstrom R. Risk factors for fractures of the distal forearm: A population based case control study. Osteoporosis Int 1994;4:298-304.

9 Hutchinson TA, Polansky SM, Feinsten AR. Postmenopausal estrogens protect against fractures of hip and menopausal estrogens protect against fractures of hip and

10 Weiss NS, Ure CL, Ballard JH, Williams AR, Daling JR Decreased risk of fractures of the hip and lower forearm with postmenopausal use of estrogen. N Eng Med $\mathcal{F} 1980$; 303:1195-8

11 Ettinger B, Genant HK, Cann CE. Long term estrogen replacement therapy prevents bone loss and fractures. Ann Intern Med 1985;102:319-24.

12 Cooper C, Hannaford P, Croft P, Kay CR. Oral contraceptive pill use and fractures in women: a prospective study. Bone 1993;14:41-5.

13 Johnell $\mathrm{O}$, Nilsson BE. Lifestyle and bone mineral mass in peri-menopausal women. Calcif Tiss Int 1984;36:354-6.

14 Goldsmith NF, Johnston JO. Bone mineral: effects of ora contraceptives, pregnancy and lactation. F Bone foint Surg contraceptives, pre

15 Dequeker J, Rutten V, Verstraeten A, Geusens P. Effect of menarche, parity, lactation and use of oral contraceptives on peripheral and axial bone mass. In: Christiansen $\mathrm{C}$, Johansen JS, Riis BJ, eds. Osteoporosis 1987. Copenhagen Osteopress ApS, 1987;432-4.

16 Nelson M, Hague GF, Cooper C, Bunker VW. Calcium intake in the elderly: validation of a dietary questionnaire. $\mathcal{f}$ Human Nut Diet 1988;1:115-27.

17 Stata Corporation. Stata reference manual. Release 3.1. 6th ed. College Station, TX: Stata, 1993.

18 Gutin B, Kasper MJ. Can vigorous exercise play a role in osteoporosis prevention? A review. Osteoporosis Int 1992 2:55-69.

19 Pocock NA, Eisman JA, Yeates MG, Sambrook PN, Eberl $\mathrm{S}$. Physical fitness is a major determinant of femoral neck and lumbar spine bone mineral density. $\mathcal{F}$ Clin Invest 1986 78:618-21.

20 Fiatarone MA, Marks EC, Ryan ND, Meredith CN, Lipsit LA, Evans WJ. High intensity strength training in nonagenarians: effects on skeletal muscle. $\mathscr{f} A M A$ 1990;263: 3029-34

21 Aniansson A, Zetterberg C, Hedberg M, Henriksson KG Impaired muscle function with aging: a background factor in the incidence of fractures of the proximal end of the femur. Clin Orthop 1984;191:193-201.

22 White MK, Martin RB, Yeates RA, Butcher RL, Radin EL The effects of exercise on the bones of postmenopausal women. Int Orthopaedics 1984;7:209-14.

23 Tylavsky FA, Anderson JJB, Talmage RV, Taft TN. Are calcium intakes and physical activity patterns during adolescence related to radial bone mass of white college-age females. Osteoporosis Int 1992;2:232-40. 